$\Phi=5$

\title{
Occupational Health and Safety legislative compliance in the construction sites in Windhoek, Namibia
}

\author{
Nghitanwa Emma Maano ${ }^{1 *}$, Zungu Lindiwe ${ }^{2}$ \\ ${ }^{1}$ School of Nursing, University of Namibia \\ ${ }^{2}$ Department of Health Studies, University of South Africa, Pretoria \\ *Corresponding author E-mail:enghitanwa@unam.na
}

\begin{abstract}
Non compliances towards occupational health and safety legislations has been on increase globally which leads to higher incidence of occupational accidents, injuries and diseases. The aim of the study is to determine the presence of occupational hazards in the construction industry and to investigate the occupational health and safety provision and compliance among construction sites in Windhoek. A quantitative, cross-sectional, descriptive design was used to conduct the study. Census sampling was used to include ten construction sites with project running during data collection time and whose site managers agreed to participate in the study. Data was collected in ten construction sites with the site inspection checklist to assess the occupational hazards and OHS compliance in participated construction sites. Data was analysed with SPSS software. The study findings indicated that occupational hazards are prevalent in the construction industry, but there is poor mechanism to control hazards and to prevent hazard exposures. Furthermore, most construction sites are non compliant towards OHS legislations. It is recommended that OHS legislations should be enforced to promote the OHS in the construction industry.
\end{abstract}

Keywords: Compliance; Hazard; Legislation; Occupational Health; Occupational Safety.

\section{Introduction}

Occupational health and safety (OHS) refers to the science of workplace hazard anticipation, recognition, evaluation and control that could impair the health and well-being of workers, workplaces surrounding communities and the environment (Alli,2008). The construction workers' health and safety have indeed been of great concern globally due to the hazardous nature of the work processes (Pesantes-Tavares, 2011). Construction work is dynamic in nature and characterised by constant changes in the working environment, poor working and environment conditions, and exposing workers to potential hazards such as noise, dust, vibration and ergonomic conditions (Pinto et al., 2011).

The International Labour organization (ILO) set up international standards such as conventions that should be ratified by all member states, including Namibia, in order to maintain health and safety of all workers at workplaces. The following conventions were developed : Convention 155 of 1981(Occupational health and Safety Convention, ILO Convention 167 of 1988 (Safety and Health in construction Convention), Occupational health services Convention, 1985 (No. 161) Promotional framework for the occupational safety and health Convention 2006(No.187) Working environment (air pollution, noise and vibration) Convention1977 No. 148) Chemical convention 1990 (No. 170).However, Namibia has not yet ratified any of these conventions which are hampering the OHS of workers in the construction industry.

Globally, there is high rate of occupational accidents, injuries and diseases, due to the non compliances towards OHS international or national requirements among employers in the construction industry (Tam, et al., 2014).Furthermore, construction workers are exposed to hazards such as physical, chemical, psychological and ergonomic hazards (Olson et al.,2016; Muema et al., 2015) which may lead to occupational injuries (Eppenberger\&Haupt ,2009). The results from the literatures indicate that the employers' ignorance of the ILO's legal guidelines on occupational health and safety at workplaces exposes workers to the risk of occupational injuries (Tam et al., 2014). In addition, the employers' negative attitudes and ignorance toward occupational health and safety practices also contributes to high rates of injuries in the construction industries(Zen \&Ismail 2011).This view is supported by the findings from the study by Ale et al., ( 2008) on construction workers in the Netherland, which indicate that many occupational injuries and fatalities are the results of either the failure of the management to put safety measures in place or poor worker attention to safety measures during construction work.

For instance, India's construction sector is largely characterised by an unorganised workforce and hardly follows standard regulations laid down by the government agencies (Beriha, 2012). Smallwood and Ajayi (2009) conducted a cross sectional self-administered questionnaires in their study on 339 South African construction workers, which found out that top management support of OHS is important for the allocation of resources towards OHS implementation, but supervisors at operational level should ensure OHS procedures, policies and practices are adhered to (Smallwood \& Ajayi , 2009).

Thailand strengthens its country's OHS compliance in construction companies through the requirement that companies must submit, during tendering processes, their safety management programs in construction stating how accidents and injuries would be prevented during construction work and indicating how compliant they would be to OHS (Ngamthampunpol, 2008).Similarly, construction companies in Japan with poor safety records are penalised and prohibited to tender (Lam, 2001). 
The Labour Act, No 11 of 2007 section 101 (Republic of Namibia, 2007) and the Regulations relating to the health and safety of employees at work (No 1561997)(Republic of Namibia 1997) were constituted to provide guidelines on health and safety at work in Namibia. The regulations (No 156 of 1997) require all employers to promote and maintain the well-being of their employees during worksite activities and consider health and safety during the execution of projects (Republic of Namibia, 1997). Furthermore, section 3 of the regulation, as stipulated in Regulation no 156 of 1997, states that employers should implement the occupational health and safety management programs that assist in the prevention of injury, diseases and accidents and lead to high productivity (Republic of Namibia, 1997). Employers in the construction sector are therefore expected to ensure the safety of workers and machineries in the workplace as well as consider that the work is done according to ergonomic principles (Republic of Namibia, 1997).

However, the health and safety of workers in Namibia's construction industry remains a challenge for the sector as reported in the 2014 Ministry of Labour and Social Welfare annual report (Ministry of Labour,Industrial relations and Employment creation of Namibia, 2014). Some workers have no access to OHS as some construction sites lack developed OHS programs, a condition that has a negative impact on construction workers (Ministry of Labour, Industrial relations and Employment creation of Namibia, 2014). The employers and workers usually justify this anomaly by citing reasons such as, "it has been done like that since our forefathers" and financial constraints. Nevertheless, companies are unaware that it is more costly to deal with injuries and fatalities than to prevent them from occurring (Link and Haimbodi, 2011). However, the labour inspectors reported that most industries in Namibia, including the construction sector, are noncompliant to OHS legislations (Ministry of Labour, Industrial relations and Employment creation of Namibia, 2016). Only $10 \%$ of the workplaces inspected during the 2015/2016 financial year were found to be in good compliance with OHS legislations (Ministry of Labour, Industrial relations and Employment creation of Namibia, 2016).

\section{Objectives}

The objectives of this study were to:

- Determine the occupational health and safety hazards prevalent in the construction industry of Windhoek in Namibia

- Investigate the occupational health and safety legislative provisions and compliance among construction sites in Windhoek, Namibia.

\section{Methodology}

A quantitative, cross-sectional, descriptive and contextual approach was applied in this study. The target population was all construction sites in Windhoek, Namibia with project running during data collection time. The study's inclusion criteria was all construction sites in the Windhoek with projects running during data collection time, from October 2014 to March 2015.There were fifteen (15) construction sites in operation in Windhoek during the study. Due to the limited number of construction sites in Windhoek during the study time, census sampling was used and all fifteen (15) construction site managers were approached to give the permission to the study. However, three construction site managers did not agree for the study to take place in their construction sites. Two construction sites were used for pilot test and had to be excluded from the main study. The data collection tool was adjusted before the main study according to the feedback from the pilot test. Structured site inspection checklist was used to collect the information regarding the presence of occupational hazards and OHS legislative compliances in ten Windhoek construction sites. Therefore, the data was collected from ten construction sites using a site inspection checklist developed by the researchers. The site inspection checklist consisted of questions developed based on the Regulations relating to health and safety of employees at work
(No 156 of 1997 ) and the World Health Organization healthy workplace model ( Burton, 2010). The questions were aimed at assessing for the legal compliances towards those legislative framework. The times for site inspection were organised with the site managers or the focal persons appointed by site managers. Data was entered in to the SPSS software data analysis program and was coded. Data was analysed with SPSS version 23 with the assistance of the professional statistician. Descriptive statistics was used to analyse the data regarding occupational hazards and OHS legislative compliance in the study sites.

\section{Results}

\subsection{Occupational hazards prevalence on the study sites}

Inspection surveys were conducted in the construction industry to investigate common occupational hazards prevalent at study sites. The analysis shows that various types of hazards were prevalent at the study sites and these include physical, chemical and ergonomic hazards, as described below.

\subsubsection{Physical hazards}

The study shows that all physical hazards, such as noise, dust, vibration and non-ionized radiation, were found at all construction sites. Examples of the observed physical hazard include wholebody vibration resulting from the use of heavy machinery, as shown in figure 1 .

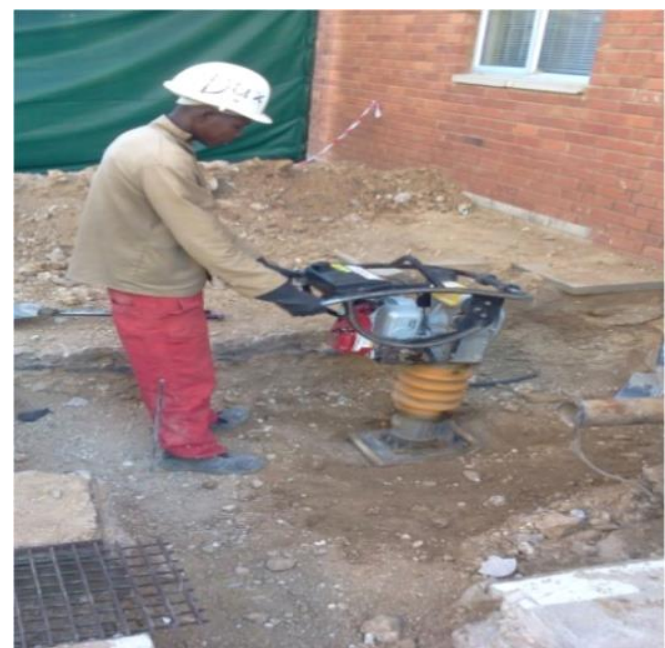

Fig. 1: Picture depicting a construction worker using a jack hammer at a construction site.

\subsubsection{Chemical hazards}

An analysis of the inspection conducted to assess the presence of chemical hazards at the construction sites shows that all study sites had chemical hazards such as gases, fumes, mists and aerosol. The workers at all 10 inspected construction sites were observed conducting activities which expose them to chemical hazards. These activities include:

- Welding which produces welding fumes and gases such as carbon monoxide.

- Arc welding that produces welding fumes.

- Spray painting where the paint changes into a mist thus become highly volatile and toxic.

\subsubsection{Ergonomic hazards}

The analysis shows that ergonomic hazards were identified at all study sites as workers were observed lifting heavy loads, performing repetitive movements, bending and twisting and working in awkward postures as shown in the pictures below. The pictures in figure $2,3,4$, and 5 were taken at some construction sites in order 
to validate the findings regarding ergonomic hazards observed during the site inspection.

\subsubsection{Repetitive movement}

Figure 2 shows a construction worker plastering a wall. The job requires a repetitive movement and awkward posture for him to work with hands above the shoulder level for an extended period and excessive reaching to plaster the wall above the head height. In addition, the plastering work requires the worker to perform repetitive movement of bending to get the plaster from the trolley, putting it on the hawk, and spreading the plaster on the wall using the float. The plastering activity involves repetitive movement of the arm, shoulder, neck and waist.

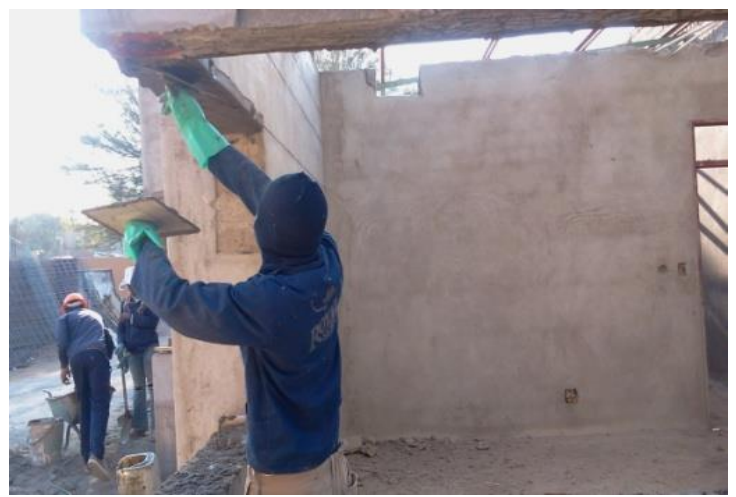

Fig. 2:Picture depicting a construction worker performing repetitive movements.

\subsubsection{Working in an awkward posture}

The photograph in figure 3 , showing a worker using a core drilling machine to make a hole in the wall, depicts an image of a worker who spends an extended period in an awkward posture. It can be noted that the worker is performing work on a very low surface which requires him to kneel or squat. The awkward posture strains the worker's knees, lower back and the neck.

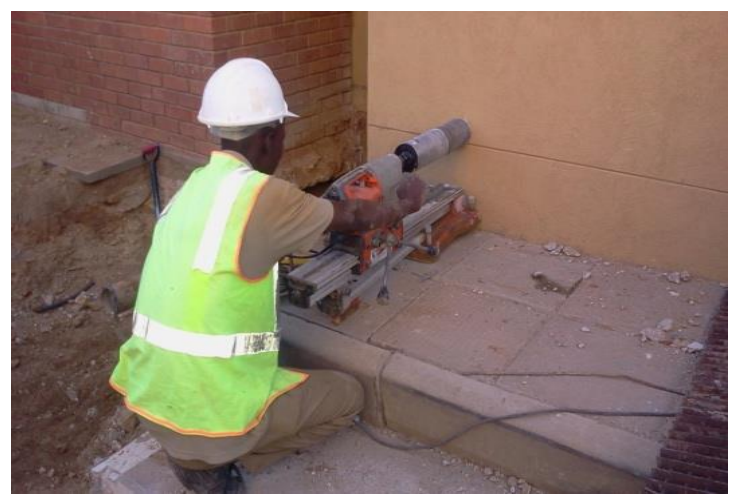

Fig. 3: Picture depicting a worker exposed to vibration whiles adopting an awkward posture at the study site.

\subsubsection{Lifting and carrying heavy load at construction sites}

Depicted in figure 4 is a worker carrying a heavy load resulting in strains over the neck and left shoulder. Material handling and frequent lifting of objects strains the shoulder and arms. The picture shows a worker with both hands holding the load to secure it, which causes both arms to be above the shoulder level.

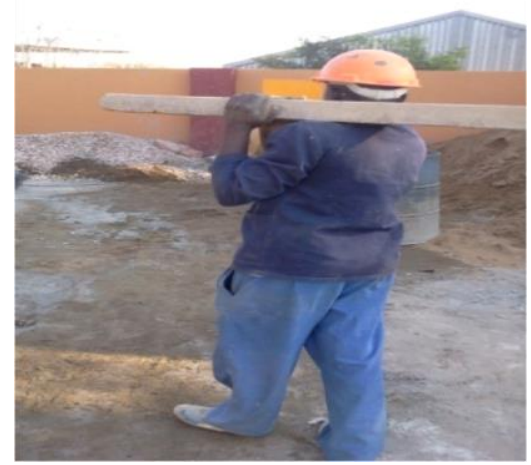

Fig.4:A Photograph showing a construction worker lifting heavy loads.

\subsubsection{Bending and twisting}

Bending and twisting is one of the ergonomic hazards observed at the construction sites during the site inspection.Figure 5 portrays the photograph of bricklayers laying bricks in the bending positions. Bending for a longer period could lead to back pain.

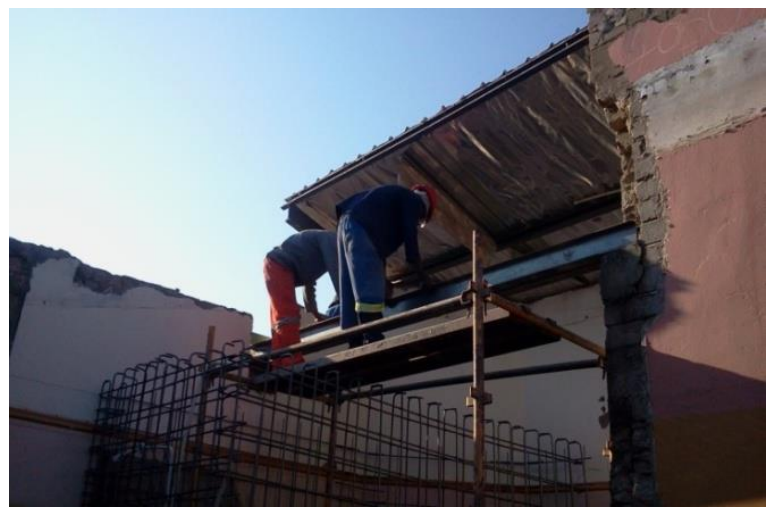

Fig. 5:A photograph showing construction workers performing work in bending positions.

\subsubsection{Hazard identification and control in construction sites}

The study shows that hazardous operations were identified at $40 \%$ of construction site. In addition, the analysis shows that safety checks were carried out before work commences at $40 \%$ construction sites. Furthermore, the analysis indicates that systems were put in place to manage the hazards and risks at $50 \%$ of the construction sites and there were details on how incidents should be notified at $50 \%$ construction sites.

However, there was no survey conducted to determine the noise level at all construction sites. Furthermore, the analysis indicates that the researcher did not find any safety measures that were meant to control vibration at all inspected construction sites. Nevertheless, the analysis reveals that the prevention of dust generation was evident at $50 \%$ construction sites. Finally, the analysis also shows that $60 \%$ construction sites had no waste management policy.

\subsection{Occupational health and safety management system}

Regarding the OHS management system, the analysis shows that $40 \%$ of the construction sites had OHS officers and OHS committees. In addition, $70 \%$ of the construction sites had been inspected by government labour officers during the period after the initiation of recent projects. The analysis also shows that people and transport movement controls were observed at $90 \%$ of the construction sites. It was also found out that $70 \%$ of the construction sites had safety signs displayed on sites. 


\subsection{Personal protective equipment (PPE) provision and usage}

The researcher observed, during inspection surveys conducted at all 10 construction sites, whether workers were using PPE while performing their duties. The analysis shows that workers at $50 \%$ of the construction sites were using PPE such as blue overalls, face masks and safety boots, while other $50 \%$ construction workers were not using PPE as depicted in figure 6.Furthermore, 50\% of construction sites were observed to have workers with PPE that was in good condition and not worn out. Surprisingly, only $30 \%$ of the construction sites had a list of workers who had been trained on PPE use.

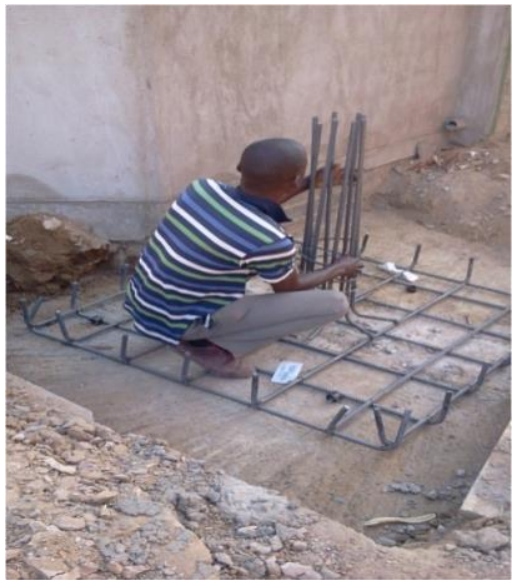

Fig. 6:A Picture of a construction worker not wearing any PPE.

\subsection{Provision of welfare facilities at construction sites}

The analysis of data regarding the provision of welfare facilities shows that only $30 \%$ of the construction sites had adequate toilet facilities for males and females. Furthermore, $40 \%$ of the construction sites did not have adequate changing rooms for construction workers. The analysis also indicates that all construction sites had have rest rooms nor smoking designated areas. Nevertheless, all inspected construction sites had drinking water that is separate from the toilet available.

\subsection{Electric safety andwork equipment safety at con- struction sites}

Construction sites were inspected for the provision of electric safety at work. The analysis shows that $60 \%$ construction sites had notices prohibiting unauthorised persons from handling or interfering with electric apparatuses. In addition, plugs, sockets, extension cords and electrical equipment were not defect nor were they damaged at $90 \%$ of the construction sites. However, all construction sites had electrical conductors that were protected through insulation. In fact, $80 \%$ of construction sites had their switchboards closed and locked.

The study also found out that $60 \%$ of the construction sites had instruction on emergency isolation switch and supply cutting.In addition, no electrical wires were found lying in water at all construction sites. However, no portable electrical equipment were safely checked nor labelled for the next inspection at all construction sites. Furthermore, $50 \%$ of the construction sites had electrical cables that were clear from walkways. Construction sites where inspected to determine the aspect of work equipment safety based on OHS compliance. The analysis shows that $90 \%$ of the construction sites had ladders that were in good condition and not damaged. Moreover, $60 \%$ of the construction sites had their machines guarded. User instructions were available for machinery equipment stationed at $80 \%$ construction sites. However, only $20 \%$ of the construction sites had inspection records for work equipment kept on site.

\subsection{Emergency preparedness and first aid services at construction sites}

The analysis, shows that $60 \%$ of the construction sites had emergency plans, a list of contacts such as the ambulance, fire andpolice in case of emergency, and had arrangements in place with the hospital or ambulances in case of emergency referral. Furthermore, the analysis shows that all construction sites had no safety box minutes. Finally, $60 \%$ construction sites had registers of available emergency equipment and locations on the construction sites.

Information about compliance regarding the provision of first aid services at the construction sites is explained as follow. Notably, $80 \%$ of the construction sites had first aid stations. Furthermore, $90 \%$ of the construction sites had first aid kits. However, certified first aiders and first aid manuals were only available at $10 \%$ of the construction sites. The analysis further shows that $70 \%$ of the construction sites had written procedures on how to transport injured workers to the hospitals. Finally, only $20 \%$ construction sites had first aid registers kept on the sites.

\subsection{Availability of fire safety systems and procedures at construction sites}

An analysis of data regard to the provision of fire safety services at the construction sites shows that $70 \%$ of the construction sites had fire prevention procedures in place. Furthermore, $40 \%$ of the construction sites had fire instructions informing the workers about what to do in case of a fire outbreak posted in an open and public space. However, the analysis shows that all construction sites had no appointed fire warden to coordinate fire activities nor were fire drills performed or recorded to make the workers aware of what is required in case of a fire. Though the analysis shows that $90 \%$ of the construction sites had fire extinguishers readily available $10 \%$ construction site had no fire extinguishers. It was also noted that fire extinguishers at $60 \%$ of the construction sites had expired. Workers at $70 \%$ construction sites had been trained on the usage of fire extinguishers. Furthermore, 50\% construction sites had emergency escape routes that were kept clear. However, the assembly points for evacuation procedures were known to the workers at $40 \%$ sites only.

\section{Discussion}

\subsection{Nature of occupational hazards in the construction industry}

The current study revealed the presence of hazards on all study sites such as physical, chemical and ergonomics hazards. The current findings revealed that noise hazards were present at all study sites. Similar findings were reported by several authors, such as Leensen et al., (2011) with regard to the Dutch construction industry, and $\mathrm{Li}$ et al., (2016:721) in their assessment of the health impact of construction noise in China, who also found out that noise is a common hazard in the construction industry.Furthermore, the current findings showed that all study sites had dust hazards. Similar findings reported dust as a common hazard in the construction industry, as noted in those from $\mathrm{Wu}$ et al (2016)regarding the study about mitigation of construction dust pollution in China and Verbeeck and Ivanon's (2013) study that confirms the construction workers' exposure to dust at the construction sites.

In addition, the current study found out that all the study sites in Windhoek had vibration hazards. Similarly, authors such as Singh and Khan (2014) in their study on India's construction industry, Simeonov et al., (2011) focusing on the USA's construction workers and Muema et al., (2015) in their assessment of the construction workers' awareness of OHS hazards in Kenya, reported on the presence of vibration in the construction industry. The present study showed that all study sites had non-ionised radiation haz- 
ards. In support, Janicak's (2008) investigation of construction industry electrocution-related fatalities in the USA and Geminiani's study (2008) on the South African construction industry, reported radiation as a common hazard in the construction industry.

It was also observed that all the investigated study sites have chemical hazards such as gases, fumes, mist and aerosols. Similar findings were also reported by several authors including, Chi and Han (2013) with regard to the USA's construction industry and Meo et al.(2013)in the study on Saudi Arabian construction workers. The above-mentioned authors' studies underscored the prevalence of chemical hazards in the construction industry, a reality also observed in the findings from the study on Windhoek's construction industry.

Ergonomic hazards were present at all study sites. Several authors made similar findings and these include Boschman et al., (2015) in their study on ergonomic measures usage among construction workers in The Netherland, Garcia- Herrrero et al., (2012) in their analysis of the influence of working conditions on occupational accidents in Spain, and Hunting, Haile and Nessel'"s (2015) study on the USA's construction industry. These authors stated that ergonomic hazards were present in the construction industry. Furthermore, Smallwood and Ajayi's (2009) study on the South African construction industry and that by Smallwood (2011) focusing on the designers knowledge, perceptions and practices towards construction materials mass and density in SA, found out that ergonomic hazards are a major concern in the construction industry.

\subsection{Hazard identification and control}

The current findings revealed that three-fifths of study sites do not identify hazardous operations. A study conducted by Mwanaumo and Thwala (2012) on Botswana's construction industry which reveals that construction workers lack the awareness of hazard identification support the findings of this study. However, the current study finding is against the findings from Ngamthampunpol's (2008) studyon the Thai construction industry, whereby risk assessment and job safety analysis was found to be conducted at the majority of the studied construction sites. The current study also revealed further that safety checks were carried out before work commenced at only two-fifths of construction sites. A previous study conducted in Uganda reported a similar finding which indicates that safety checks were carried out at only $14 \%$ of the construction sites (Irumba 2014). A different observation in reflected in the study findings by Phoya (2012)regarding the Tanzania construction industry where safety teams from the majority of construction sites were found to conduct safety checks that involved going around the sites to identify potential hazards and put up control measures such as barricade the hazards.

Furthermore, this current study revealed that surveys to determine the noise levels were not conducted at all study sites. This study finding, however, differs from those made by several authors in their studies, which determined the noise level at the construction sites. For example, Zhang, Zhai and Yang's studies (2014) on China's construction industry found that the country's construction industry conducted noise surveys. The performance of activities seeking to prevent the generation of dust was also observed to be taking place at half of the study sites. This finding regarding the current study is differ in the study by Wu et al., (2016) which assesses the source and mitigation of construction dust in China and found out that the majority of construction workers were not aware of dust mitigation measures.

\subsection{Occupational health and safety management system and personal protective equipment provision}

The current study findings indicated that three-fifths of construction sites have appointed OHS officers. This finding is different from the study by Irumba (2012) on Uganda's construction indus- try which found that only $30 \%$ of construction sites appointed OHS officers.

The current study findings revealed that most of construction workers did not wear PPE while performing work, which put them at risk of hazard exposure. Similar findings are reported by Phoya's ( 2012) study among Tanzanian construction workers; Cheng et al's (2010) on Taiwan's construction industry, where the majority of construction workers were observed not wearing PPE during the studies. However, a study conducted by Acharya (2014) on the utilisation of PPE among industrial workers in Nepal found to the contrary that above two-thirds of construction workers regularly used relevant PPE at work.

Furthermore, the findings of this study indicated that just below one-third of construction sites had a list of workers trained on PPE use, which is almost similar the observations made by Acharya's study (2014) on PPE utilisation in Nepal, which indicates that just below one fourth of construction workers were trained on PPE utilisation at workplaces. Training on PPE use is therefore, important if their use is to be effective use.

\subsection{Welfare facilities provision}

The current study indicated that only one-third of the study sites have adequate toilet facilities demarcated for males and females. This finding is almost similar to that from Baruah's (2010) study on the opportunities and challenges faced by women in India's construction industry that found out that over two-thirds of construction sites had no toilet facilities.

\subsection{Electric safety and work equipment safety}

The current study findings show that no portable electrical equipment was safely checked and tagged for the next inspection at all study sites. According to the Worksafe $\mathrm{Bc}(2008)$ report, all portable electrical equipment should be tested on regular bases and tagged to indicate the name of the competent person who conducted the testing and the date for the next inspection should be indicated.

It emerged from the current study that only one fifth of construction sites had inspection records for work equipment kept on site. The section 59 to 62 of the Regulations relating to health and safety of employees at work (No 156 of 1997) stipulate that an employer must ensure the safety of machinery at work by safeguarding, training and educating workers about the machinery, as well as maintaining and controlling the machineries (Republic of Namibia, 1997).

\subsection{Emergencies preparedness and first aid services provision}

Findings from this current study show that three-fifths of study sites have emergency plans and lists of contact details for the ambulance, fire and police services in case of emergency, and there were arrangements with the hospitals and ambulance in case of emergency referrals. The current study findings are is similar with the requirement by ILO-OSH (2001), which states that emergency plans and response arrangements should be established and maintained at all workplaces. Surprisingly, it emerged, from the findings of this study that, all study sites had no safety box minutes. The lack safety box minutes contrasts with the study conducted by Olson et al (2016) in the USA to investigate the toolbox talk in fatality prevention which found out that $75 \%$ participants indicated that tool box talks were conducted at construction sites. The findings of this current study illustrated that no trained certified first aider was found at the majority of study sites and first aid manuals were only available at few study sites. This supports Irumba's (2014) study on the Ugandan construction industry, which found out that the majority of construction sites had no first aiders. 


\subsection{Fire safety services}

The current study findings showed that all study sites had no fire warden and no fire drills were performed nor recorded for workers to know what is required in case of a fire. Furthermore, the findings of the current study showed that the majority of study sites had fire extinguishers available; however, most of these fire extinguishers had expired.The current study findings are against the requirements of the provision of regulation 43 (3) for the Regulations relating to health and safety of employees at work (No 156 of 1997) which states that an employer is required to ensure that fire extinguishers are accessible at workplaces, maintain and guarantee that they are in good working order, and instruct workers on the proper usage of fire extinguishers (Republic of Namibia, 1997).

\section{Conclusion}

The study findings indicate that different types of hazards are prevalent in the study sites, however there is poor mechanism of hazard control and hazard exposure preventive measures .The current study findings demonstrated that there is a higher level of non compliance towards OHS legislations in the Windhoek construction industry. The study findings revealed that OHS management system is not implemented in most study sites which affect the overall compliance on OHS legislations which negatively affect the health, wellbeing and safety of construction workers. The researchers recommend for the Ministry of Labour, Industrial relations and Employment creation to ensure the enforcement of the OHS legislations especially by requesting for OHS plan before the approval of the construction projects.

\section{Ethical issues}

The study was given ethical clearance from the University of South Africa (UNISA) ethical committee before data collection process. The researchers also sought and obtained permission from the site managers of the construction sites which participated in the study before data collection.Furthermore, the researchers sought and obtained the permission from the Khomas Regional Council as Windhoek is located in the Khomas region and regional council offices should sanction any research activities taking place in the region. The data collection tools were reassessed by the experts in OHS field to ensure that the content was related with OHS in the construction industry. The data collection tools were piloted, and then the proposed changes were incorporated according to the feedback from the pilot testing. Reliability was ensured during this study through using the same data collection tools on all ten construction sites participated in the study.

\section{References}

[1] Ale, BJM, Bellamy, LJ, Baksteen, H, Damen, M, Gossens, LHJ, Hale, AR, Mud, M, Oh, J, Papazoglou, IA \&Whiston, JY. Accidents in the construction industry in the Netherlands: An analysis of accident reports using Storybuilder. Reliability Engineering and System Safety. $\quad$ 93: 1533.https://doi.org/10.1016/j.ress.2007.09.004

[2] Alli, BO. 2008. Fundamental principles of occupational health and safety. International Labour Office. Geneva. Switzerland.http://www.ilo.org/global/publications/books/WCMS_093550/ lang--en/index.htm.

[3] Acharya, SR. 2014.Utilization pattern of personal protective equipment among industrial workers of Nawalparasi, Nepal.Journal of Public Health 13(2):24 28.http://nepjol.info/index.php/HPROSPECT/article/view/11833.

[4] Baruah, B. 2010.Gender and globalization. Opportunities and constraints faced by women in the construction industry in India. Labour Studies Journal 35(2):198221.http://journals.sagepub.com/doi/abs/10.1177/0160449X083261 87.
[5] Beriha, GS, Patnaik, B \&Mahapatra, SS. 2012. Assessment of occupational health practices in Indian industries. Journal of Modelling in Management 7(2):180-200. http://www.emeraldinsight.com/doi/full/10.1108/174656612112428 04.https://doi.org/10.1108/17465661211242804.

[6] Boschman, JS, Frings-Dresen, MHW \& Van der Molen, HF. 2015. Use of ergonomic measures related to musculoskeletal complaints among construction workers : A 2-year follow-up Study. Safety and Health at Work 6(2):9096.https://www.ncbi.nlm.nih.gov/pubmed/26106507.https://doi.org/ 10.1016/j.shaw.2014.12.003.

[7] Burton, J. 2010. WHO Healthy workplace framework and model: Background and Supporting Literature and Practice. Geneva, Switzerland: WHO.http://apps.who.int/iris/handle/10665/113144.

[8] Cheng, C, Leu, S, Cheng Y, \& Lin, C. 2012.Applying data mining techniques to explore factors contributing to occupational injuries in Taiwan's construction industry.Accident Analysis and Prevention 48:214-222.

https://www.ncbi.nlm.nih.gov/pubmed/22664684.https://doi.org/10. 1016/j.aap.2011.04.014.

[9] Chi, S \& Han, S. 2013. Analyses of systems theory for construction accident prevention with specific reference to OSHA accident reports.International Journal of Project Management 31(7):10271041.

http://www.sciencedirect.com/science/article/pii/S02637863120018 09.https://doi.org/10.1016/j.ijproman.2012.12.004.

[10] Eppenberger, M \&Haupt, T. 2009.Construction worker injuries and costs - a comparative study of older and younger workers.Occupational Health Southern Africa (September/ October):613.www.occhealth.co.za/.../Construction+worker+injuries...costs... comparative + study.

[11] García-Herrero, S, Mariscal, MA, García-Rodrígues, J \&Ritzel, DO. 2012. Working conditions, psychological/physical symptoms and occupational accidents. Bayesian network models.Safety Sciences $50: 1760$ 1774.http://www.sciencedirect.com/science/article/pii/S092575351 2000926.https://doi.org/10.1016/j.ssci.2012.04.005.

[12] Geminiani, FL. 2008. A model to improve the effectiveness of the occupational health and safety inspectorate function relative to South African construction. Doctoral thesis. Nelson Mandela Metropolitan University: South Africa.http://contentpro.seals.ac.za/iii/cpro/DigitalItemViewPage.extern al ?lang=eng\&sp=1010933\&sp=T\&suite $=$ def.

[13] International Labour Organization. 2001. Guidelines on occupational safety and health management systems. Geneva. Switzerland: ILO

Publications.http://www.ilo.org/global/publications/ilobookstore/orderonli ne/books/WCMS_PUBL_9221116344_EN/lang-en/index.htm?ssSourceSiteId=safework.

[14] Irumba, R. 2014. Spatial analysis of construction accidents in Kampala, Uganda.Safety Science 64:109-120. http://www.sciencedirect.com/science/article/pii/S09257535130029 20.https://doi.org/10.1016/j.ssci.2013.11.024.

[15] Janicak, CA. 2008.Occupational fatalities due to electrocutions in the construction industry.Journal of Safety Research 39(6): 617621 .

https://www.ncbi.nlm.nih.gov/pubmed/19064047.https://doi.org/10. 1016/j.jsr.2008.10.007

[16] Jamal, H \& Khan, MK. 2006.Determinants of occupational safety and health performance in small and medium manufacturing settings.PhD Thesis. University Utara, Malaysia: Sintok, Kedah.

[17] Leensen, MCJ, Van Duivenbooden, JC, \&Dreschler, WA. 2011. A retrospective analysis of noise-induced hearing loss in the Dutch construction industry. International Archives of Occupational and Environmental Health (84):577590.https://www.ncbi.nlm.nih.gov/pubmed/21203771.https://doi.or g/10.1007/s00420-010-0606-3.

[18] Meo, SA, Alsaaran, ZF, Alshehri, MK, Khashougji, MA, Almeterk, AAZ, Almutairi, SF \&Alsaeed, SF. 2013.Work-related symptoms among building construction workers in Riyadh, Saudi Arabia.Pakistan Journal of Medical Sciences 29(96):1394 1399https://www.ncbi.nlm.nih.gov/pmc/articles/PMC3905378/.

[19] Ministry of Health and Social Services of Namibia. 2014. Annual report: 2013/2014. Windhoek: Ministry of Health and Social Services.

[20] Ministry of Labour, Industrial relations and Employment creations of Namibia. 2015. Annual report: 2014/2015. Windhoek: Ministry of Labour and Social Welfare. 
[21] Ministry of Labour, Industrial relations and Employment creation of Namibia. 2016. Annual report: 2015/2016. Windhoek: Ministry of Labour and Social Welfare.

[22] Muema, LM, Gatebe, E, Kirui, B \& Adrian, AA. 2015. Awareness of construction workers on occupational hazards, illness and injuries associated with construction industry in Mombasa County. Journal of Nursing and Health Science 4(6):7582.www.iosrjournals.org/iosr-jnhs/papers/vol4-issue6/Version 2/G04627582.pdf.

[23] Mwanaumo, E \&Thwala, WD. 2012. Construction practitioners' awareness of occupational diseases in the Botswana construction industry: An exploratory study. Occupational Health Southern Africa

$18(4): 12$

17.http://www.journals.co.za/content/ohsa/18/4/EJC124108.

[24] Ngamthampunpol, D. 2008. An assessment of Safety Management in the Thai construction industry. Doctoral Dissertation. George Washington University, United States. From :http://gradworks.umi.com/32/97/3297451.html.

[25] Olson, R, Varga, A, Cannon, A, Jones, J, Gilbert-Jones, I \&Zoller, E. 2016. Toolbox talks to prevent construction fatalities: Empirical development and evaluation. Safety Science 86:122-131. http://www.sciencedirect.com/science/article/pii/S09257535160004 61.https://doi.org/10.1016/j.ssci.2016.02.009.

[26] Pesantes-Tavares, E. 2011. Construction worker health:A webbased approach to selecting alternatives to hazardous procedures. Doctoral thesis. University of Florida: Florida.http://gradworks.umi.com/35/31/3531533.html.

[27] Pinto, A, Nunes, IL \&Ribeiro, RA. 2011. Occupational risk assessment in construction industry - Overview and reflection. Safety Science 49(5):616-624. http://www.sciencedirect.com/science/article/pii/S09257535110000 51.https://doi.org/10.1016/j.ssci.2011.01.003.

[28] Phoya, S., 2012.The practice of risk assessment, communication and control health and safety risk management in building construction sites.Degree thesis. Chalmers University of Technology: Gothenburg,

Sweden.http://publications.lib.chalmers.se/publication/164071-healthand-safetyriskmanagement-on-building-constuction-sites-intanzania-the-practice-of-risk-ass.

[29] Republic of Namibia.1997.Regulations relating to the health and safety of employees at work. Regulation R.156, in terms of the Labour Act, 1992 (Act No 6, 1992, as amended). Windhoek: Government Printers.

[30] Republic of Namibia.2007.Labour Act, No 11, 2007. Windhoek: Government Printers.

[31] Simeonov, P, Hsiao, H, Powers, J, Ammons, D, Kau, T \&Amendola, A. 2011. Postural stability effects of random vibration at the feet of construction workers in simulated elevation. Applied Ergonomics 42(5):672681.https://www.ncbi.nlm.nih.gov/pubmed/21071015.https://doi.or g/10.1016/j.apergo.2010.10.002.

[32] Smallwood, J. 2011. Mass and density of construction materials Designers' knowledge, perceptions, and practices. Ergonomics South Africa 23(1):28-41. http://www.ajol.info/index.php/esa/article/view/124348.

[33] Smallwood, J \&Ajayi, O. 2009. The impact of training on construction ergonomics knowledge and awareness. Ergonomics South Africa

38.http://www.ajol.info/index.php/esa/article/view/124303

[34] Tam, CM, Zeng, SX \& Deng, Z. M., 2004.Identifying elements of poor construction safety management in China. Safety Science 42:569-

586.http://www.sciencedirect.com/science/article/pii/S0925753503 000602.https://doi.org/10.1016/j.ssci.2003.09.001.

[35] Verbeek, J \&Ivanov, I. 2013. Essential occupational safety and health interventions for low- and middle-income countries: An overview of the evidence. Safety and Health at Work 4(2):77-83. https://www.ncbi.nlm.nih.gov/pmc/articles/PMC3732143/.https://d oi.org/10.1016/j.shaw.2013.04.004

[36] WorkSafeBc. 2008.How to implement a formal occupational health and safety program. http://www.worksafebc. Com/publications/health and safety/ by topic/assets/pdf/ how to implement ohs. Pdf.

[37] Wu, Z, Zhang, X \& Wu, M. 2016.Mitigating construction dust pollution: State of the art and the way forward.Journal of Cleaner Production 112:1658 1666.http://www.sciencedirect.com/science/article/pii/S095965261 5000190.https://doi.org/10.1016/j.jclepro.2015.01.015.

[38] Zhang, H, Zhai, D \& Yang, YN. 2014. Simulation-based estimation of environmental pollutions from construction processes. Journal of
Cleaner

Production

$76.85-94$.

http://cat.inist.fr/?aModele=afficheN\&cpsidt=28523143.

[39] Zin, SM \& Ismail, F. 2012. Employers' behavioural safety compliance factors toward occupational, safety and health improvement in the construction industry. Procedia - Social and Behavioral Sciences

(36):742-751. http://www.sciencedirect.com/science/article/pii/S18770428120054 84.https://doi.org/10.1016/i.sbspro.2012.03.081. 